ARTICLE

Received 18 Sep 2014 | Accepted 30 Jan 2015 | Published 3 Mar 2015

DOI: $10.1038 /$ ncomms7468

OPEN

\title{
Molecular magnetic switch for a metallofullerene
}

\author{
Bo Wu${ }^{1}$, Taishan Wang ${ }^{1}$, Yongqiang Feng ${ }^{1}$, Zhuxia Zhang ${ }^{1}$, Li Jiang ${ }^{1} \&$ Chunru Wang ${ }^{1}$
}

The endohedral fullerenes lead to well-protected internal species by the fullerene cages, and even highly reactive radicals can be stabilized. However, the manipulation of the magnetic properties of these radicals from outside remains challenging. Here we report a system of a paramagnetic metallofullerene $\mathrm{Sc}_{3} \mathrm{C}_{2} @ \mathrm{C}_{80}$ connected to a nitroxide radical, to achieve the remote control of the magnetic properties of the metallofullerene. The remote nitroxide group serves as a magnetic switch for the electronic spin resonance (ESR) signals of $\mathrm{Sc}_{3} \mathrm{C}_{2} @ \mathrm{C}_{80}$ via spin-spin interactions. Briefly, the nitroxide radical group can 'switch off' the ESR signals of the $\mathrm{Sc}_{3} \mathrm{C}_{2} @ \mathrm{C}_{80}$ moiety. Moreover, the strength of spin-spin interactions between $\mathrm{Sc}_{3} \mathrm{C}_{2} @ \mathrm{C}_{80}$ and the nitroxide group can be manipulated by changing the distance between these two spin centres. In addition, the ESR signals of the $\mathrm{Sc}_{3} \mathrm{C}_{2} @ \mathrm{C}_{80}$ moiety can be switched on at low temperatures through weakened spin-lattice interactions.

\footnotetext{
${ }^{1}$ Key Laboratory of Molecular Nanostructure and Nanotechnology, Beijing National Laboratory for Molecular Sciences, Institute of Chemistry, Chinese Academy of Sciences, Beijing 100190, China. Correspondence and requests for materials should be addressed to T.W. (email: wangtais@iccas.ac.cn) or to C.W. (email: crwang@iccas.ac.cn).
} 
E ndohedral fullerenes are constructed by putting atoms or clusters inside fullerene cages, which isolates the internal species with environments, so even those high-reactive species can be well stabilized inside the fullerene cages ${ }^{1-6}$. For example, paramagnetic endohedral fullerenes such as $\mathrm{N} @ \mathrm{C}_{60}$ (refs 7-10), Sc@C $\mathrm{C}_{82}$ (refs 11,12), Y@C $\mathrm{C}_{82}$ (refs 13,14), $\mathrm{Sc}_{3} \mathrm{C}_{2} @$ $I_{h}-\mathrm{C}_{80}$ (refs 15-17) and so on, encapsulating radicals inside the fullerene cages, show also remarkable high stability, and they can be kept in air under room temperature for a long time, especially for endohedral metallofullerenes (EMFs). Considering the paramagnetic endohedral fullerenes usually show long electron spin relaxation and coherence times, they are expected to have potential applications in many fields such as spin labelling, spintronics, quantum computing and so on ${ }^{18}$.

For paramagnetic EMFs, the electronic spin resonance (ESR) technique is a powerful tool to detect the spin distributions and spin-nucleus couplings on internal species ${ }^{19-21}$. By means of ESR, it was revealed that the magnetic property of the internal species can be roughly manipulated by changing the dynamic movement of internal species. For example, under room temperature the internal $\mathrm{Y}_{2}$ cluster in $\mathrm{Y}_{2} @ \mathrm{C}_{79} \mathrm{~N}$ has a free rotation that leads to a symmetric ESR pattern, but along with the temperature decreasing, the free motion of $\mathrm{Y}_{2}$ is hindered, leading to spin anisotropy and an asymmetric ESR pattern ${ }^{22}$. In addition, the spin characters and couplings in $\mathrm{Sc}_{3} \mathrm{C}_{2} @ \mathrm{C}_{80}$ was observed to change largely upon chemical modification of the fullerene cage due to the restricted $\mathrm{Sc}_{3} \mathrm{C}_{2}$ cluster ${ }^{17}$.

For better applying the paramagnetic EMFs in quantum information process and molecular devices, however, it is still a challenge to finely manipulate their magnetic property. Recently, Turro et al. chemically modified the $\mathrm{H}_{2} @ \mathrm{C}_{60}$ with a nitroxide radical, and observed an indirect but strong magnetic communication between the electron spin of nitroxide paramagnet and the nuclear spin of encaged $\mathrm{H}_{2}$ (refs 23-28). This finding provides a valuable clue for us on manipulating the magnetic property of paramagnetic EMFs via a foreign paramagnet ${ }^{29}$. Since a strong spin-spin interaction between the paramagnetic fullerene molecule and the paramagnet is expected, thus the magnetic property of paramagnetic EMFs may be controlled by the attached paramagnet.

Herein, we report detailed studies on the fine manipulation for paramagnetic $\mathrm{Sc}_{3} \mathrm{C}_{2} @ \mathrm{C}_{80}$ by connecting it with a paramagnet of nitroxide radical. The target system $\mathrm{FSc}_{3} \mathrm{C}_{2} @ \mathrm{C}_{80} \mathrm{PNO}^{\bullet}$ contains two kinds of spins localizing on $\mathrm{Sc}_{3} \mathrm{C}_{2} @ \mathrm{C}_{80}$ and nitroxide radical, respectively. The remote nitroxide group serves as a magnetic switch for the ESR signals of $\mathrm{Sc}_{3} \mathrm{C}_{2} @ \mathrm{C}_{80}$ through spin-spin interactions. The paramagnetic properties of the metallofullerene $\mathrm{Sc}_{3} \mathrm{C}_{2} @ \mathrm{C}_{80}$ can be delicately adjusted by changing the temperature, varying the distance between the two spin centres, or simply quenching the nitroxide radical.

\section{Results}

Preparation of metallofullerene and its derivatives. Metallofullerene $\mathrm{Sc}_{3} \mathrm{C}_{2} @ \mathrm{C}_{80}$ was synthesized by the Kräschmer-Huffman arc-discharging method ${ }^{30}$ and isolated by multi-stage highperformance liquid chromatography. Two $\mathrm{Sc}_{3} \mathrm{C}_{2} @ \mathrm{C}_{80}$ derivatives, $\mathrm{FSc}_{3} \mathrm{C}_{2} @ \mathrm{C}_{80} \mathrm{PNOH}$ and $\mathrm{FSc}_{3} \mathrm{C}_{2} @ \mathrm{C}_{80} \mathrm{PNO}^{\bullet}$, were first synthesized through a Prato reaction ${ }^{31}$, respectively, as shown in Fig. 1a,b. The structures and spin density distributions of $\mathrm{FSc}_{3} \mathrm{C}_{2} @ \mathrm{C}_{80} \mathrm{PNOH}$ and $\mathrm{FSc}_{3} \mathrm{C}_{2} @ \mathrm{C}_{80} \mathrm{PNO}^{\bullet}$ were calculated as well, as shown in Fig. $1 \mathrm{c}$,d. The $\mathrm{FSc}_{3} \mathrm{C}_{2} @ \mathrm{C}_{80} \mathrm{PNOH}$ has one spin centre that is localized on $\mathrm{Sc}_{3} \mathrm{C}_{2} @ \mathrm{C}_{80}$, whereas the $\mathrm{FSc}_{3} \mathrm{C}_{2} @ \mathrm{C}_{80} \mathrm{PNO}^{\bullet}$ has two unpaired spins localizing on the $\mathrm{Sc}_{3} \mathrm{C}_{2} @ \mathrm{C}_{80}$ moiety and nitroxide radical, respectively.
The ESR analysis of metallofullerene with a nitroxide radical. $\mathrm{Sc}_{3} \mathrm{C}_{2} @ \mathrm{C}_{80}$ is a typical paramagnetic endohedral fullerene. As reported previously, the ESR spectrum of the pristine $\mathrm{Sc}_{3} \mathrm{C}_{2} @ \mathrm{C}_{80}$ shows a symmetric pattern with 21 resonant lines, however, those of $\mathrm{Sc}_{3} \mathrm{C}_{2} @ \mathrm{C}_{80}$ derivatives showed a distorted pattern with a greatly increased amount of resonant lines ${ }^{17}$. Therefore, ESR spectroscopy was first employed to reveal the electron spin characters of $\mathrm{FSc}_{3} \mathrm{C}_{2} @ \mathrm{C}_{80} \mathrm{PNOH}$ and $\mathrm{FSc}_{3} \mathrm{C}_{2} @ \mathrm{C}_{80} \mathrm{PNO}^{\bullet}$.

As shown in Fig. 1e, the ESR spectrum of $\mathrm{FSc}_{3} \mathrm{C}_{2} @ \mathrm{C}_{80} \mathrm{PNOH}$ was measured and analysed. Because the $I_{h}$ symmetry of $\mathrm{Sc}_{3} \mathrm{C}_{2} @ \mathrm{C}_{80}$ is broken down after chemical modification, the original three equivalent scandium nuclei $\left(I_{\mathrm{Sc}}=7 / 2\right)$ are classified into two groups in $\mathrm{FSc}_{3} \mathrm{C}_{2} @ \mathrm{C}_{80} \mathrm{PNOH}$, in which one group contains a single Sc nucleus $(g=1.9948$, hyperfine coupling constants $(\mathrm{hfcc})=8.5 \mathrm{G})$, and the other group contains two equivalent $\mathrm{Sc}$ nuclei $(\mathrm{hfcc}=5.0 \mathrm{G})$. In comparison, the previously studied $\mathrm{Sc}_{3} \mathrm{C}_{2} @ \mathrm{C}_{80}$ fulleropyrrolidine shows a similar ESR pattern with hfcc of $8.6 \mathrm{G}$ (one Sc nucleus) and $4.8 \mathrm{G}$ (two Sc nuclei), respectively ${ }^{17}$. These ESR results reveal that the $\mathrm{FSc}_{3} \mathrm{C}_{2} @ \mathrm{C}_{80} \mathrm{PNOH}$ has a same reaction site with that of $\mathrm{Sc}_{3} \mathrm{C}_{2} @ \mathrm{C}_{80}$ fulleropyrrolidine ${ }^{17}$.

However, the ESR study of $\mathrm{FSc}_{3} \mathrm{C}_{2} @ \mathrm{C}_{80} \mathrm{PNO}^{\bullet}$ showed only three resonant lines $(g=2.0026, a=15.5 \mathrm{G})$ that are derived from nitroxide radical $\left(I_{\mathrm{N}}=1\right)$, and the ESR signals of $\mathrm{Sc}_{3} \mathrm{C}_{2} @ \mathrm{C}_{80}$ moiety were not observed, as illustrated in Fig. 1f. The current results reveal that the ESR signals of $\mathrm{Sc}_{3} \mathrm{C}_{2} @ \mathrm{C}_{80}$ can be switched off by paramagnetic nitroxide radical through spin-spin interaction. Thus it is interesting that the nitroxide radical group can serve as a remote controller for the ESR signals of $\mathrm{Sc}_{3} \mathrm{C}_{2} @ \mathrm{C}_{80}$ moiety. Vividly, if the ESR signals of $\mathrm{Sc}_{3} \mathrm{C}_{2} @ \mathrm{C}_{80}$ moiety are regarded as an indicating lamp, the nitroxide radical group can switch it off.

To reveal the mechanism of how the ESR signals of $\mathrm{Sc}_{3} \mathrm{C}_{2} @ \mathrm{C}_{80}$ moiety are switched off by the nitroxide radical, we synthesized $\mathrm{FSc}_{3} \mathrm{~N} @ \mathrm{C}_{80} \mathrm{PNO}^{\bullet}$ in a same way for comparison. $\mathrm{Sc}_{3} \mathrm{~N} @ \mathrm{C}_{80}$ is a diamagnetic molecule, and no spin-spin interaction is expected for $\mathrm{FSc}_{3} \mathrm{~N} @ \mathrm{C}_{80} \mathrm{PNO}^{\bullet}$. The signal intensity of $\mathrm{FSc}_{3} \mathrm{~N} @ \mathrm{C}_{80} \mathrm{PNO}^{\bullet}$ was observed to be stronger than that of $\mathrm{FSc}_{3} \mathrm{C}_{2} @ \mathrm{C}_{80} \mathrm{PNO}^{\bullet}$ at the same concentration (0.151 p.p.m.). That is to say, the spin-spin interactions weaken both of the ESR signals of $\mathrm{Sc}_{3} \mathrm{C}_{2} @ \mathrm{C}_{80}$ and nitroxide radical (Supplementary Fig. 1).

For $\mathrm{FSc}_{3} \mathrm{C}_{2} @ \mathrm{C}_{80} \mathrm{PNO}^{\bullet}$, the spin-spin interactions can be expressed as below:

$$
E_{\text {dip }}=\frac{\mu_{0}}{4 \pi} g^{2} \beta_{e}^{2}\left[\frac{S_{1} \times S_{2}}{r^{3}}-\frac{3\left(S_{1} \times r\right)\left(S_{2} \times r\right)}{r^{5}}\right]
$$

Where $E_{\text {dip }}$ is the energy of dipolar coupling, and $r$ is the dipoledipole distance.

In fact, the spin-spin interactions between $\mathrm{Sc}_{3} \mathrm{C}_{2} @ \mathrm{C}_{80}$ and nitroxide radical broaden the resonance lines and lower the line intensity in the meantime, so the line width $(\Delta H)$ is adopted to represent the ESR line intensity and interpret the spin-spin interactions ${ }^{32,33}$.

In general, for paramagnetic molecules the ESR line width is inversely proportional to the relaxation time $(T)$, including the spin-lattice relaxation time $\left(T_{1}\right)$ and the spin-spin relaxation time $\left(T_{2}\right)$ :

$$
\Delta H=\frac{h}{2 \pi g \beta}\left(\frac{1}{T_{1}}\right)+\frac{h}{2 \pi g \beta}\left(\frac{1}{T_{2}}\right)
$$

Therefore, the strong dipole-dipole interactions between nitroxide radical and $\mathrm{Sc}_{3} \mathrm{C}_{2} @ \mathrm{C}_{80}$ in $\mathrm{FSc}_{3} \mathrm{C}_{2} @ \mathrm{C}_{80} \mathrm{PNO}^{\bullet}$ reduced the spin-spin relaxation time $\left(T_{2}\right)$, resulting in decreased ESR signals of both $\mathrm{Sc}_{3} \mathrm{C}_{2} @ \mathrm{C}_{80}$ and nitroxide radical moieties. 
a

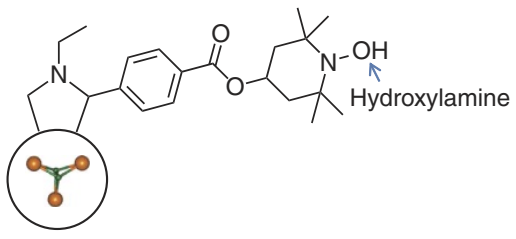

C

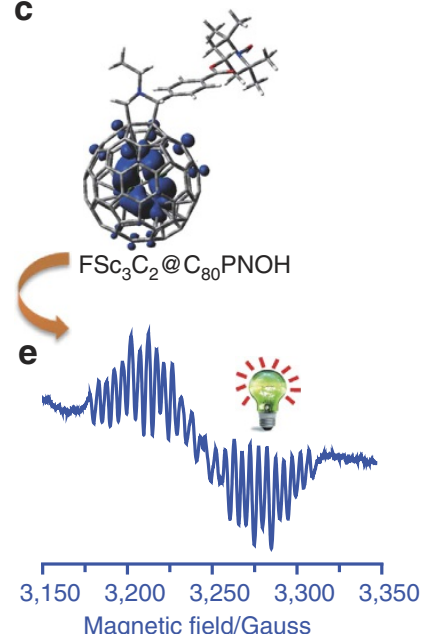

b
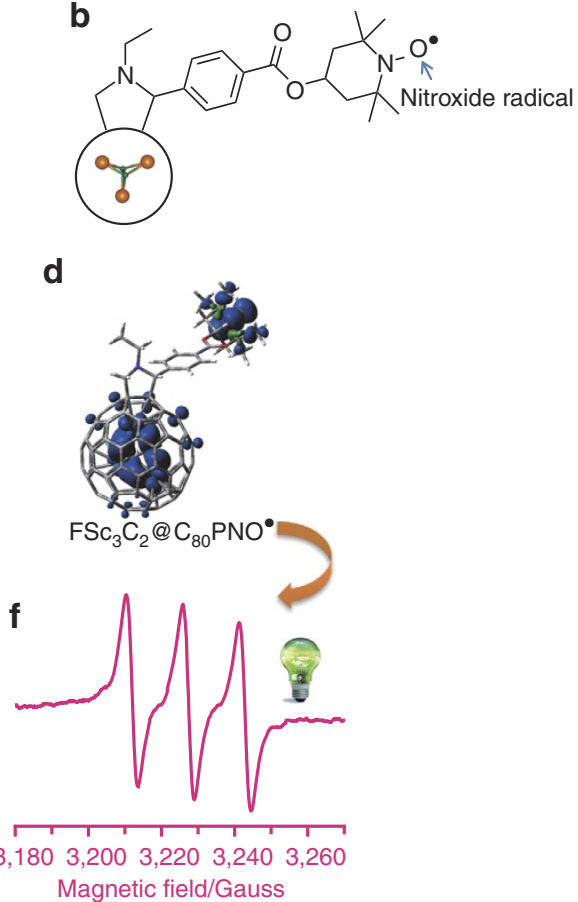

Figure 1 | Magnetic switch for the ESR signals of $\mathbf{S c}_{\mathbf{3}} \mathbf{C}_{\mathbf{2}} @ \mathbf{C}_{\mathbf{8 0}}$. (a) The structure of $\mathrm{FSC}_{3} \mathrm{C}_{2} @ \mathrm{C}_{80} \mathrm{PNOH}$. (b) The structure of $\mathrm{FSc} \mathrm{C}_{3} @ \mathrm{C}_{20} \mathrm{PNO}^{\bullet}$. (c) The calculated structure and spin density distributions of $\mathrm{FSc}_{3} \mathrm{C}_{2} @ \mathrm{C}_{80} \mathrm{PNOH}$. (d) The calculated structure and spin density distributions of $\mathrm{FSc}_{3} \mathrm{C}_{2} @ \mathrm{C}_{80} \mathrm{PNO}^{\bullet}$. (e) The ESR spectrum of $\mathrm{FSc}_{3} \mathrm{C}_{2} @ \mathrm{C}_{80} \mathrm{PNOH}$ at $293 \mathrm{~K}$ in toluene. (f) The ESR spectrum of $\mathrm{FSC}_{3} \mathrm{C}_{2} @ \mathrm{C}_{80} \mathrm{PNO}$ at $293 \mathrm{~K}$ in toluene. The lamps in e and $\mathbf{f}$ show the 'on' and 'off' states of $\mathrm{Sc}_{3} \mathrm{C}_{2} @ \mathrm{C}_{80}$ ESR signals, respectively.

Note that the transformation between $\mathrm{FSc}_{3} \mathrm{C}_{2} @ \mathrm{C}_{80} \mathrm{PNO}^{\bullet}$ and $\mathrm{FSc}_{3} \mathrm{C}_{2} @ \mathrm{C}_{80} \mathrm{PNOH}$ is reversible, that is, the nitroxide radical in $\mathrm{FSc}_{3} \mathrm{C}_{2} @ \mathrm{C}_{80} \mathrm{PNO}^{\bullet}$ turns into the corresponding hydroxylamine derivative $\left(\mathrm{FSc}_{3} \mathrm{C}_{2} @ \mathrm{C}_{80} \mathrm{PNOH}\right)$ using $p$-toluenesulfonohydrazide, and the $\mathrm{FSc}_{3} \mathrm{C}_{2} @ \mathrm{C}_{80} \mathrm{NOH}$ can be back to $\mathrm{FSc}_{3} \mathrm{C}_{2} @ \mathrm{C}_{80} \mathrm{PNO}^{\bullet}$ by means of oxidation with copper acetate (Supplementary Fig. 2). Therefore, the magnetic property of $\mathrm{Sc}_{3} \mathrm{C}_{2} @ \mathrm{C}_{80}$ can be easily manipulated by a chemical method, and the remote nitroxide group serves as a switch in this process.

The distance-dependent ESR signals. On the basis of equation (1), the spin-spin interactions between $\mathrm{Sc}_{3} \mathrm{C}_{2} @ \mathrm{C}_{80}$ and nitroxide radical moieties can be efficiently reduced by elongating their distance, thus two other $\mathrm{Sc}_{3} \mathrm{C}_{2} @ \mathrm{C}_{80}$ and nitroxide radical derivatives, that is, $\mathrm{FSc}_{3} \mathrm{C}_{2} @ \mathrm{C}_{80} \mathrm{PNO}^{\bullet}-2$ and $\mathrm{FSc}_{3} \mathrm{C}_{2} @ \mathrm{C}_{80} \mathrm{PNO}^{\bullet}-3$, were synthesized with longer distances between these two spin centres. The pulsed ESR measurements on $\mathrm{FSc}_{3} \mathrm{C}_{2} @ \mathrm{C}_{80} \mathrm{PNO}^{\bullet}$ and $\mathrm{FSc}_{3} \mathrm{C}_{2} @ \mathrm{C}_{80} \mathrm{PNO}^{\bullet}-2$ revealed that the $T_{2}$ of nitroxide radical becomes longer when the distance of these two spins increases (Supplementary Fig. 3). As shown in Fig. 2, it is obvious that the ESR signals of $\mathrm{Sc}_{3} \mathrm{C}_{2} @ \mathrm{C}_{80}$ also gradually boost up along with the distance increasing, and this process is like lighting a lamp and making it brighter.

However, the increased chain length between $\mathrm{Sc}_{3} \mathrm{C}_{2} @ \mathrm{C}_{80}$ and nitroxide radical would result in a strengthened spin-lattice interaction, which will bring another line-broadening effect for both nitroxide radical and $\mathrm{Sc}_{3} \mathrm{C}_{2} @ \mathrm{C}_{80}$ moiety. The spin-lattice relaxation time $\left(T_{1}\right)$ can be expressed as below:

$$
\frac{1}{T_{1}}=\frac{2 \pi g \beta_{e}}{h}\left(B_{x}^{2}+B_{y}^{2}\right) \frac{\tau_{\mathrm{c}}}{1+\tau_{\mathrm{c}}^{2} \omega_{s}^{2}}
$$

Where $B_{x}^{2}$ and $B_{y}^{2}$ are mean square amplitudes of the fluctuating fields along the $x$ - and $y$-directions, and $\tau_{\mathrm{c}}$ is the correlation time of the motion that causes the fluctuation. For molecules with a spherical shape, $\tau_{\mathrm{c}}$ in liquid solution corresponds to the rotational correlation time $\tau_{\mathrm{r}}$, which can be approximated by the StokesEinstein relation:

$$
\tau_{\mathrm{r}}=\frac{4 \pi \eta a^{3}}{3 k_{B} T}
$$

Where $a$ is the rotationally effective radius of the molecule, and $\eta$ is the viscosity of the solvent. In liquids with a low viscosity $\left(\tau^{2}{ }_{c} \omega^{2}{ }_{s} \approx 1\right)$, the $T_{1}$ is dependent of $a^{3}$, and $T_{1}$ decreases with increasing the rotationally effective radius of the molecule. Therefore, increasement of the molecular size would shorten the $T_{1}$, leading to weaker ESR signals.

Since $\mathrm{FSc}_{3} \mathrm{C}_{2} @ \mathrm{C}_{80} \mathrm{PNO}^{\bullet}, \mathrm{FSc}_{3} \mathrm{C}_{2} @ \mathrm{C}_{80} \mathrm{PNO}^{\bullet}-2$ and $\mathrm{FSc}_{3} \mathrm{C}_{2} @$ $\mathrm{C}_{80} \mathrm{PNO}^{\bullet}-3$ are all rigid structural molecules, the intramolecular dipolar coupling strength $(D)$ can be estimated, in which the coupling strength of $\mathrm{FSc}_{3} \mathrm{C}_{2} @ \mathrm{C}_{80} \mathrm{PNO}^{\bullet}$ with $r=1.38 \mathrm{~nm}$ was estimated to be about $24.3 \mathrm{MHz}$ following the classical point dipole approximation, and those of $\mathrm{FSc}_{3} \mathrm{C}_{2} @ \mathrm{C}_{80} \mathrm{PNO}^{\bullet}-2$ and $\mathrm{FSc}_{3} \mathrm{C}_{2} @ \mathrm{C}_{80} \mathrm{PNO}^{\bullet}-3$ were estimated to be about 11.2 and $5.48 \mathrm{MHz}$, respectively.

The temperature-dependent ESR signals. It is known that the spin-lattice relaxation time $\left(T_{1}\right)$ of unpaired spin is tightly related to the temperature. As expressed in equation (3), the decreasement of temperature would reduce the $B_{x}$ and $B_{y}$, and then increase the $T_{1}$ and lead to higher ESR line intensity. Therefore, the temperature-dependent ESR studies of $\mathrm{FSc}_{3} \mathrm{C}_{2} @ \mathrm{C}_{80} \mathrm{PNO}^{\bullet}$ were performed, as shown in Fig. 3. It can be observed that no ESR signal of $\mathrm{Sc}_{3} \mathrm{C}_{2} @ \mathrm{C}_{80}$ was observed at $293 \mathrm{~K}$, but since $253 \mathrm{~K}$, the ESR signals of $\mathrm{Sc}_{3} \mathrm{C}_{2} @ \mathrm{C}_{80}$ appeared together with three strong resonant lines of nitroxide radical, and continuously increased along with the temperature further decreasing. Finally at $213 \mathrm{~K}$, the ESR signals of $\mathrm{Sc}_{3} \mathrm{C}_{2} @ \mathrm{C}_{80}$ moiety can be clearly observed. The electrostatic spin-phonon 

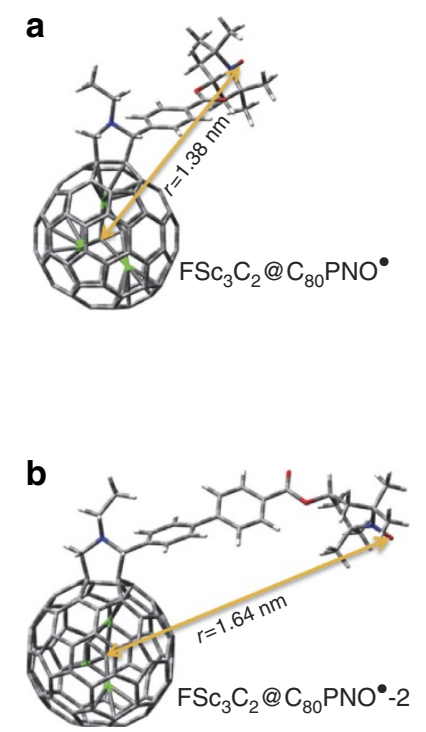
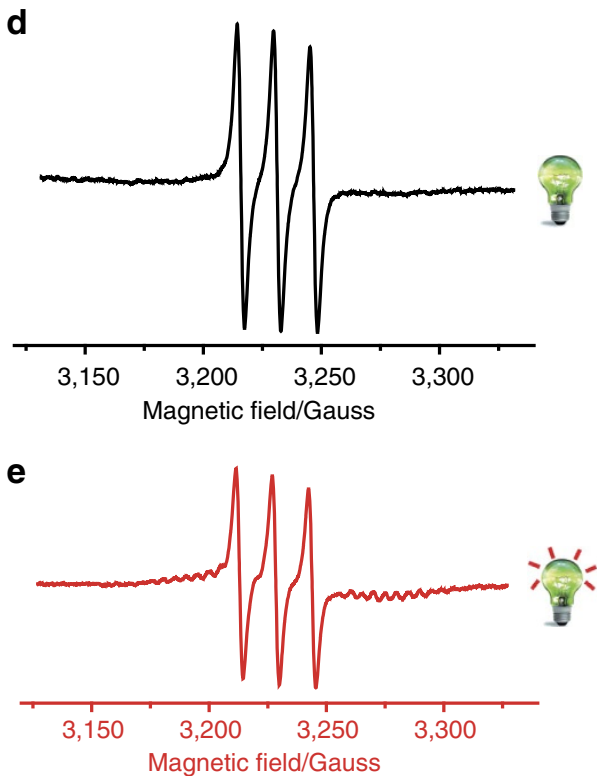

$\mathbf{f}$

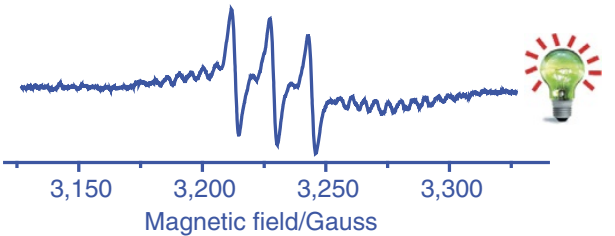

Figure 2 | Distance-dependent ESR signals of $\mathbf{S c}_{\mathbf{3}} \mathbf{C}_{\mathbf{2}} @ \mathbf{C}_{\mathbf{8 0}}$ derivatives. (a-c) Structures of $\mathrm{FSC}_{3} \mathrm{C}_{2} @ \mathrm{C}_{80} \mathrm{PNO}^{\bullet}, \mathrm{FSc}_{3} \mathrm{C}_{2} @ \mathrm{C}_{80} \mathrm{PNO}^{\bullet}-2$ and $\mathrm{FSC}_{3} \mathrm{C}_{2} @ \mathrm{C}_{80} \mathrm{PNO} \cdot-3$. (d-f) ESR signals of $\mathrm{FSC}_{3} \mathrm{C}_{2} @ \mathrm{C}_{80} \mathrm{PNO}^{\bullet}, \mathrm{FSc}_{3} \mathrm{C}_{2} @ \mathrm{C}_{80} \mathrm{PNO} \mathrm{PNO}^{\bullet}$ and $\mathrm{FSc}_{3} \mathrm{C}_{2} @ \mathrm{C}_{80} \mathrm{PNO} \mathrm{PNO}^{\bullet} 3$ at $293 \mathrm{~K}$. The lamps in d-f show the strengthened ESR signals of $\mathrm{Sc}_{3} \mathrm{C}_{2} @ \mathrm{C}_{80}$ moiety along with the enlarged distance from nitroxide radical.

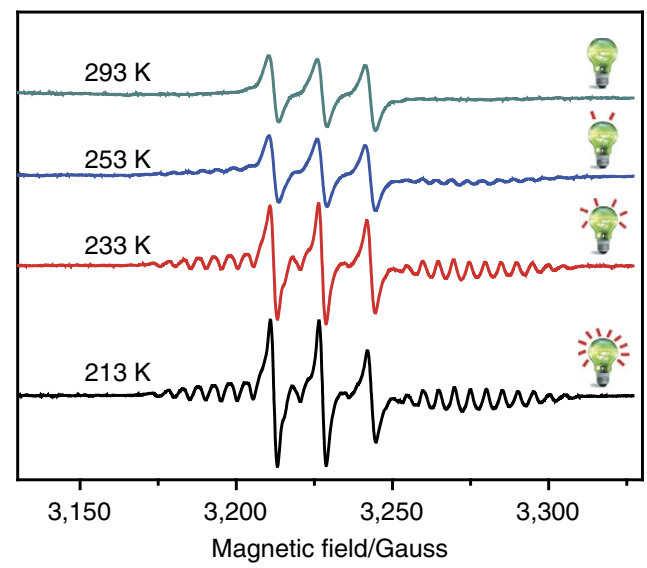

Figure 3 | Temperature-dependent ESR signals of $\mathrm{Sc}_{3} \mathrm{C}_{\mathbf{2}} @ \mathrm{C}_{80}$ derivatives. The ESR spectra of $\mathrm{FSC}_{3} \mathrm{C}_{2} @ \mathrm{C}_{80} \mathrm{PNO} \mathrm{P}^{\bullet}$ at variable temperatures in toluene solution. The lamps represent the strengthened ESR signals of $\mathrm{Sc}_{3} \mathrm{C}_{2} @ \mathrm{C}_{80}$ moiety along with the decreased temperatures.

interaction was also analysed for these temperature-dependent ESR spectra ${ }^{34}$. As the lowest temperature in our system is $213 \mathrm{~K}$, under this condition the $\mathrm{FSc}_{3} \mathrm{C}_{2} @ \mathrm{C}_{80} \mathrm{PNO}^{\bullet}$ toluene solution is still in liquid state, so the spin-phonon interaction is rather small and negligible. From the temperature-dependent ESR spectra, it can be seen that the temperature also can light the signals of $\mathrm{Sc}_{3} \mathrm{C}_{2} @ \mathrm{C}_{80}$ moiety in $\mathrm{FSc}_{3} \mathrm{C}_{2} @ \mathrm{C}_{80} \mathrm{PNO}^{\bullet}$ and make it brighter.
Table 1 | ESR data.

\begin{tabular}{lcc} 
Temperature (K) & $\begin{array}{c}\text { Line width of } \\
\text { nitroxide (G) }\end{array}$ & $\begin{array}{c}\text { Line width of } \\
\mathbf{S c}_{\mathbf{3}} \mathbf{C}_{\mathbf{2}} @ \mathbf{C}_{\mathbf{8 0}} \mathbf{( G )}\end{array}$ \\
\hline 293 & 3.17 & - \\
253 & 3.08 & 2.63 \\
233 & 2.47 & 2.37 \\
213 & 2.35 & 2.13 \\
\hline ESR, electronic spin resonance. & & \\
The ESR spectra line width of nitroxide and $\mathrm{Sc}_{3} \mathrm{C}_{2} @ \mathrm{C}_{80}$ in $\mathrm{FSC}_{3} \mathrm{C}_{2} @ \mathrm{C}_{80} \mathrm{PNO} \cdot$ at variable \\
temperatures.
\end{tabular}

Moreover, it should be noted that the ESR signals of the nitroxide were also enhanced. Therefore, along with the temperature decreasing, the prolonged $T_{1}$ enhances not only the ESR signals of $\mathrm{Sc}_{3} \mathrm{C}_{2} @ \mathrm{C}_{80}$ moiety, but also those of the nitroxide radical (Supplementary Fig. 4). The line widths of $\mathrm{Sc}_{3} \mathrm{C}_{2} @ \mathrm{C}_{80}$ moiety and nitroxide radical are listed in Table 1.

\section{Discussion}

Through connecting the paramagnetic metallofullerene $\mathrm{Sc}_{3} \mathrm{C}_{2} @ \mathrm{C}_{80}$ with a nitroxide radical, we have realized the manipulation of ESR signals of $\mathrm{Sc}_{3} \mathrm{C}_{2} @ \mathrm{C}_{80}$. The remote nitroxide group serves as a magnetic switch for ESR signals of $\mathrm{Sc}_{3} \mathrm{C}_{2} @ \mathrm{C}_{80}$, that is, the paramagnetic nitroxide group can 'switch off the ESR 
signals of $\mathrm{Sc}_{3} \mathrm{C}_{2} @ \mathrm{C}_{80}$ moiety. It was revealed that the spin-spin interactions between $\mathrm{Sc}_{3} \mathrm{C}_{2} @ \mathrm{C}_{80}$ and nitroxide radical play a key role in realizing this kind of magnetic switch. Moreover, through increasing the distance between $\mathrm{Sc}_{3} \mathrm{C}_{2} @ \mathrm{C}_{80}$ and nitroxide radical, or decreasing the temperature, we can finely adjust the paramagnetic property of $\mathrm{Sc}_{3} \mathrm{C}_{2} @ \mathrm{C}_{80}$.

Such controllable paramagnetism and switchable ESR signals have potential applications in quantum information processing and molecular devices. For example, these magnetic molecules can be fabricated to a single molecule membrane for data storage considering their transferrable two electron spin states $(0 / 1)$, which can be written and read out by means of scanning tunnelling microscope. In addition, these magnetic molecules can be utilized as a probe for the reaction transition state considering the susceptible magnetic switch of the nitroxide group.

\section{Methods}

Synthesis of $\mathbf{S c}_{\mathbf{3}} \mathbf{C}_{\mathbf{2}} @ \mathbf{C}_{\mathbf{8 0}}$ and $\mathbf{S c}_{\mathbf{3}} \mathbf{N} @ \mathbf{C}_{\mathbf{8 0}}$ derivatives. $\mathrm{Sc}_{3} \mathrm{C}_{2} @ \mathrm{C}_{80}$ and $\mathrm{Sc}_{3} \mathrm{~N} @ \mathrm{C}_{80}$ were heated with $\mathrm{N}$-ethylglycine and 2,2,6,6 tetramethylpiperidine-1-oxyl 4-formylbenzoate (1a) (Supplementary Fig. 5), which were synthesized as literature methods ${ }^{24}$ at $120^{\circ} \mathrm{C}$ to give corresponding fulleropyrrolidines with yields of nearly $50 \%$ in toluene solution for 15 and 50 min, respectively. Pure $\mathrm{FSc}_{3} \mathrm{C}_{2} @ \mathrm{C}_{80} \mathrm{PNO}{ }^{\bullet}$ and $\mathrm{FSc}_{3} \mathrm{~N} @ \mathrm{C}_{80} \mathrm{PNO}^{\bullet}$ were isolated by HPLC using Buckyprep column (Supplementary Fig. 6). $\mathrm{FSc}_{3} \mathrm{C}_{2} @ \mathrm{C}_{80} \mathrm{PNO}^{\bullet}-2$ and $\mathrm{FSc}_{3} \mathrm{C}_{2} @ \mathrm{C}_{80} \mathrm{PNO}^{\bullet}-3$ were synthesized according to same procedure used for compound $\mathrm{FSc}_{3} \mathrm{C}_{2} @ \mathrm{C}_{80} \mathrm{PNO}^{\bullet}$, except 2,2,6,6 tetramethylpiperidine-1-oxyl 4'-formylbiphenyl-4-carboxylate (2a) and 2,2,6,6 tetramethylpiperidine-1-oxyl 4'-p-terphenyl-4-carboxylate (3a) (Supplementary Fig. 7) were used.

Synthesis of $\mathbf{F S C}_{\mathbf{3}} \mathbf{C}_{\mathbf{2}} @ \mathbf{C}_{\mathbf{8 0}} \mathbf{P N O H}$. To a solution of $\sim 0.5 \mathrm{mg}$ of the nitroxide derivative $\mathrm{FSc}_{3} \mathrm{C}_{2} @ \mathrm{C}_{80} \mathrm{PNO} \mathrm{PN}^{\bullet} \sim 2 \mathrm{ml}$ toluene was added $\sim 1 \mathrm{mg} p$-toluenesulfonohydrazide, and stirred under air for about $15 \mathrm{~min}$.

Characterization of metallofullerene derivatives. Ultraviolet/visible-nearinfrared spectra of purified metallofullerene derivatives (Supplementary Fig. 8) were collected on Lambda $950 \mathrm{UV} / \mathrm{Vis} / \mathrm{NIR}$ Spectrometer (PerkinElmer Instruments). ${ }^{1} \mathrm{H}$ NMR spectra of $\mathrm{FSc}_{3} \mathrm{~N} @ \mathrm{C}_{80} \mathrm{PNOH}$ was measured in chloroform- $d$ on a Bruker $600 \mathrm{MHz}$ spectrometer (Supplementary Fig. 9).

ESR measurements of metallofullerene derivatives. ESR spectra were measured on a JEOL JEF FA200 X-band spectrometer (Supplementary Fig. 10). The samples were degassed and the oxygen was removed from the solutions. All of the samples are dissolved in toluene solution at the same concentration.

Calculations on $\mathbf{S C}_{\mathbf{3}} \mathbf{C}_{\mathbf{2}} @ \mathbf{C}_{\mathbf{8 0}}$ derivatives. Density functional theory calculations were investigated by Perdew, Burke and Enzerhof/double numerical plus polarization using the $\mathrm{DMol} 3$ code in Accelrys Materials Studio ${ }^{35,36}$.

\section{References}

1. Taylor, R. \& Walton, D. R. M. The chemistry of fullerenes. Nature 363, 685-693 (1993).

2. Popov, A. A., Yang, S. \& Dunsch, L. Endohedral fullerenes. Chem. Rev. 113, 5989-6113 (2013).

3. Yang, S., Liu, F., Chen, C., Jiao, M. \& Wei, T. Fullerenes encaging metal clusters-clusterfullerenes. Chem. Commun. 47, 11822-11839 (2011).

4. Schenning, A. P. H. J. \& George, S. J. Self-assembly: phases full of fullerenes. Nat. Chem. 6, 658-659 (2014).

5. Hollamby, M. J. et al. Directed assembly of optoelectronically active alkyl- $\pi$ conjugated molecules by adding $\mathrm{n}$-alkanes or $\pi$-conjugated species. Nat. Chem. 6, 690-696 (2014)

6. Popov, A. A. \& Dunsch, L. Structure, stability, and cluster-cage interactions in nitride clusterfullerenes $\mathrm{M}_{3} \mathrm{~N} @ \mathrm{C}_{2 \mathrm{n}}(\mathrm{M}=\mathrm{Sc}, \mathrm{Y} ; 2 \mathrm{n}=68-98)$ : a density functional theory study. J. Am. Chem. Soc. 129, 11835-11849 (2007)

7. Morton, J. J. L. et al. Electron spin relaxation of $\mathrm{N} @ \mathrm{C}_{60}$ in $\mathrm{CS}_{2}$. J. Chem. Phys. 124, 014508 (2006)

8. Morton, J. J. L. et al. The $\mathrm{N} @ \mathrm{C}_{60}$ nuclear spin qubit: bang-bang decoupling and ultrafast phase gates. Phys. Stat. Sol. 243, 3028-3031 (2006).

9. Liu, G. et al. $\mathrm{N} @ \mathrm{C}_{60}$-porphyrin: a dyad of two radical centers. J. Am. Chem. Soc. 134, 1938-1941 (2012).

10. Morton, J. J. L. et al. Environmental effects on electron spin relaxation in N@C 60. Phys. Rev. B 76, 085418 (2007).
11. Morley, G. W. et al. Hyperfine structure of Sc@ $\mathrm{C}_{82}$ from ESR and DFT. Nanotechnology 16, 2469-2473 (2005).

12. Ito, Y. et al. Magnetic properties and crystal structure of solvent-free Sc@ $\mathrm{C}_{82}$ metallofullerene microcrystals. Chem. Phys. Chem. 8, 1019-1024 (2007).

13. Kikuchi, K. et al. Characterization of the isolated $\mathrm{Y}_{8} \mathrm{C}_{82}$. J. Am. Chem. Soc. 116, 9367-9368 (1994).

14. Misochko, E. Y. et al. EPR spectrum of the $\mathrm{Y}_{82} \mathrm{C}_{82}$ metallofullerene isolated in solid argon matrix: hyperfine structure from EPR spectroscopy and relativistic DFT calculations. Phys. Chem. Chem. Phys. 12, 8863-8869 (2010).

15. Taubert, S., Straka, M., Pennanen, T. O., Sundholm, D. \& Vaara, J. Dynamics and magnetic resonance properties of $\mathrm{Sc}_{3} \mathrm{C}_{2} @ \mathrm{C}_{80}$ and its monoanion. Phys. Chem. Chem. Phys. 10, 7158-7168 (2008).

16. Wang, T. et al. Preparation and ESR study of $\mathrm{Sc}_{3} \mathrm{C}_{2} @ \mathrm{C}_{80}$ bis-addition fulleropyrrolidines. Dalton Trans. 41, 2567-2570 (2012).

17. Wang, T. et al. Spin divergence induced by exohedral modification: ESR Study of $\mathrm{Sc}_{3} \mathrm{C}_{2} @ \mathrm{C}_{80}$ fulleropyrrolidine. Angew.Chem. Int. Ed. 49, 1786-1789 (2010).

18. Krause, M. et al. Fullerene quantum gyroscope. Phys. Rev. Lett. 93, 137403 (2004).

19. Wang, T. \& Wang, C. Endohedral metallofullerenes based on spherical $\mathrm{I}_{\mathrm{h}}-\mathrm{C}_{80}$ Cage: molecular structures and paramagnetic properties. Acc. Chem. Res. 47, 450-458 (2013).

20. Sato, S. et al. Mechanistic study of the Diels-Alder reaction of paramagnetic

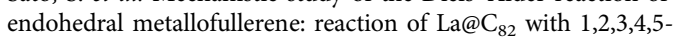
pentamethylcyclopentadiene. J. Am. Chem. Soc. 135, 5582-5587 (2013).

21. Elliott, B. et al. Spin density and cluster dynamics in $\mathrm{Sc}_{3} \mathrm{~N} @ \mathrm{C}_{80}^{-}$upon $[5,6]$ exohedral functionalization: an ESR and DFT study. J. Phys. Chem. C 117, 2344-2348 (2013).

22. Ma, Y. et al. Susceptible electron spin adhering to an yttrium cluster inside an azafullerene $\mathrm{C}_{79} \mathrm{~N}$. Chem. Commun. 48, 11570-1157 (2012).

23. Li, Y. et al. A magnetic switch for spin-catalyzed interconversion of nuclear spin isomers. J. Am. Chem. Soc. 132, 4042-4043 (2010).

24. Li, Y. et al. Distance-dependent paramagnet-enhanced nuclear spin relaxation of $\mathrm{H}_{2} @ \mathrm{C}_{60}$ derivatives covalently linked to a nitroxide radical. J. Phys. Chem. Lett. 1, 2135-2138 (2010).

25. Li, Y. et al. Distance-dependent para- $\mathrm{H}_{2} \rightarrow$ ortho- $\mathrm{H}_{2}$ conversion in $\mathrm{H}_{2} @ \mathrm{C}_{60}$ derivatives covalently linked to a nitroxide radical. J. Phys. Chem. Lett. 2, 741-744 (2011).

26. Li, Y. et al. Synthesis, isomer count, and nuclear spin relaxation of $\mathrm{H}_{2} \mathrm{O} @$ open$\mathrm{C}_{60}$ nitroxide derivatives. Org. Lett. 14, 3822-3825 (2012).

27. Turro, N. J. et al. The spin chemistry and magnetic resonance of $\mathrm{H}_{2} @ \mathrm{C}_{60}$. From the pauli principle to trapping a long lived nuclear excited spin state inside a buckyball. Acc. Chem. Res. 43, 335-345 (2009).

28. Turro, N. J. et al. Demonstration of a chemical transformation inside a fullerene. The reversible conversion of the allotropes of $\mathrm{H}_{2} @ \mathrm{C}_{60}$. J. Am. Chem Soc. 130, 10506-10507 (2008).

29. Farrington, B. J. et al. Chemistry at the nanoscale: synthesis of an $\mathrm{N} @ \mathrm{C}_{60^{-}}$ $\mathrm{N} @ \mathrm{C}_{60}$ endohedral fullerene dimer. Angew. Chem. Int. Ed. 51, 3587-3590 (2012).

30. Kroto, H. W., Heath, J. R., O'Brien, S. C., Curl, R. F. \& Smalley, R. E. C60: Buckminsterfullerene. Nature 318, 162-163 (1985).

31. Brough, P., Klumpp, C., Bianco, A., Campidelli, S. \& Prato, M. [60] Fullerenepyrrolidine-N-oxides. J. Org. Chem. 71, 2014-2020 (2006).

32. Schweiger, A. \& Jeschke, G. Principles of Pulse Electron Paramagnetic Resonance (Oxford Univ. Press, 2001)

33. Berliner, L. J., Eaton, G. R. \& Eaton, S. S. Distance Measurements in Biological Systems by EPR (Springer, 2002).

34. Abragam, A. \& Bleaney, B. Electron Paramagnetic Resonance of Transition Ions (Dover Publications, 1970).

35. Perdew, J. P., Burke, K. \& Ernzerhof, M. Generalized gradient approximation made simple. Phys. Rev. Lett. 77, 3865-3868 (1996).

36. Delley, B. An all-electron numerical method for solving the local density functional for polyatomic molecules. J. Chem. Phys. 92, 508-517 (1990).

\section{Acknowledgements}

This work was supported by the National Basic Research Program (2012CB932901), National Natural Science Foundation of China $(21203205,61227902,51472248$ and 21273006), NSAF (11179006) and the Key Research Program of the Chinese Academy of Sciences (KGZD-EW-T02). T.W. thanks the Youth Innovation Promotion Association of CAS. We thank the help from Dr Guoquan Liu in Max Planck Institute for pulsed ESR measurements.

\section{Author contributions}

T.W. conceived and designed the experiments. T.W. and C.W. wrote the paper. Experiments were carried out by B.W. The ESR data were analysed by T.W. and B.W. Calculations were carried out by Z.Z. All authors discussed the results and contributed to manuscript preparation. 


\section{Additional information}

Supplementary Information accompanies this paper at http://www.nature.com/ naturecommunications

Competing financial interests: The authors declare no competing financial interests.

Reprints and permission information is available online at http://npg.nature.com/ reprintsandpermissions/
How to cite this article: $\mathrm{Wu}, \mathrm{B}$. et al. Molecular magnetic switch for a metallofullerene. Nat. Commun. 6:6468 doi: 10.1038/ncomms7468 (2015).

(c) (i) This work is licensed under a Creative Commons Attribution 4.0 International License. The images or other third party material in this article are included in the article's Creative Commons license, unless indicated otherwise in the credit line; if the material is not included under the Creative Commons license, users will need to obtain permission from the license holder to reproduce the material. To view a copy of this license, visit http://creativecommons.org/licenses/by/4.0/ 